\title{
Managing Print-Based Weeding Projects in Academic Libraries
}

\begin{abstract}
Weeding" is the process of removing information resources from a collection. As a public relations quagmire, it is one of the most challenging tasks that an information manager may face. With the rise of election resources, printbased weeding projects are on the rise. It is integral that information managers have the necessary skills to carry out this endeavour. This paper examines the best practices for managing a print-based weeding project in an academic library, based on recent literature and the author's work experience. A set of recommendations for choosing material to remove, developing workflows, managing public relations and finding solutions for discarded material are put forward.
\end{abstract}

\begin{abstract}
About the Author: Hilary is a forward-thinking Information Management (IM) professional, with boundary-spanning skill sets that blend the library field and information technology needs of tomorrow. Hilary earned her Bachelor of Arts Honours in History and English at the University in Toronto. She then went on to pursue a Master's of European History at the University College London. As a current Master of Library and Information Studies candidate and an employee of Dalhousie Libraries, Hilary looks to take the best IM practices from the past, and apply them to build a better future using cutting-edge IM techniques. This paper was originally written for INFO 6560: Information Resources Management.
\end{abstract}




\section{Introduction}

Weeding is perhaps the most dreaded of all library tasks. Yet removing collection material that is no longer of value to users is an essential part of good collections management practices. Many librarians and library staff try to avoid this process (Dubicki, 2008; Metz \& Gray, 2005). Literature on the topic reveals that weeding can be one of the most challenging tasks a library and its staff can conduct (Terrance, 2013a). For this reason, it is imperative that librarians fully understand the factors involved in weeding projects. What is it about weeding that causes this trepidation? What are the benefits and risks of undertaking such a project? What are common challenges encountered while weeding? What are the accepted best practices for deaccessioning material? Each library may have different answers to these questions, depending on the type of collection and the needs of its user base. This essay will explore the above questions with a focus on weeding physical materials from academic library collections. While the focus of this paper is narrow, the implications for best practices may inform weeding projects in other types of libraries including collections in government and corporate settings. This paper considers how the practice of weeding print items has changed since the mid1990s. Since this time, the rise of electronic resources has impacted how the physical collection is managed. In addition, in recent years the development of improved information systems has allowed librarians to collect more data about how their collections are used.

These systems allow collection managers to make informed, evidenced-based decisions about collection maintenance.

\section{Why Weed?}

Many people may wonder why it is necessary for a library to weed its materials. First, it is important to understand that there is a difference between a library and a repository. A library is an evolving entity, which must adapt over time to ensure that it houses the most current and useful information for its users. While it is the responsibility of a library to provide information to a particular community, that information must be relevant. In an academic library, the collection must also support current curriculum. A repository on the other hand, such as the legal depository at the British Library, may seek to preserve as much print material as it possibly can (British Library, 2014). Most libraries are not repositories. Since physical space is limited, most 
library collections will reach a point where they need to have their print collections weeded (Ronadin, Simonsen, \& Vogh, 2009).

In addition to selecting relevant materials to add to a collection, a librarian must also know when to remove materials that are no longer of value to the library's users. There are many reasons that a monograph in an academic library should be weeded. These reasons may include: outdated or obsolete material, old editions, lack of use, poor condition that requires replacement, unnecessary duplication, and/or lack of relevancy to course curriculum. The removal of unused and underused material helps make way for new, more relevant material (Terrance, 2013a). Weeding is one way to ensure that the space occupied by print items is in the best interest of a library's user base. This is especially true given the changing influence of information over time.

It is also important to note that in today's interconnected world, individual academic libraries are not isolated entities. Many libraries are part of consortia with similar institutions (Snyder, 2014). Services such as document delivery and inter-library loan make it unnecessary for one library to house all materials on a given subject. These services make it easy for users to order less used materials not available at their own institution's library from another institution's library. Items ordered through these services are regularly received in a timely manner. As this paper will explore below, the literature on this topic is primarily focused on case studies. There is a need for a synthesis of best practices that professionals can use to develop and manage deselection projects. This paper will draw conclusions on recent best practices for developing and managing weeding projects by analyzing recurrent themes in various case studies.

\section{Weeding Practices Since the Mid-1990s}

In recent years, many large academic and research libraries have undertaken large weeding projects (e.g. the library at Virginia Polytechnic Institute) (Metz \& Gray, 2005). To some extent, this may be because many libraries built in the 1960s and 1970s have reached capacity. However, one must also consider how the rise of electronic resources has changed the way libraries connect users with information.

One reason that electronic resources have become so popular is because they have the potential to improve access for the user. This is especially true in the case of electronic 
journals, which can now be easily accessed through online databases. Users no longer need to visit their academic library to access a journal article. Instead, they can access this material via a proxy link provided by their home institution. This improved access means that electronic material has increased value for the library user.

Library statistics demonstrate that since 1996, there has been a downward trend in the circulation statistics of print items (Matlak, 2010). Also since 1996, libraries have increased their adoption of electronic resources (2010). This change in format (from print to electronic) has major implications for the physical space previously occupied by these now electronic resources.

The adoption of electronic resources may often duplicate pre-existing physical material. Since physical space in libraries is at a premium, growing collections of electronic resources have led libraries to reevaluate the space currently being used by physical resources (Banks, 2002; Steele, 2008). During the reevaluation process, many academic libraries decided to remove physical material no longer of value, or duplicated in electronic format, in order to make much needed space for additional study areas or new technological equipment (Steele, 2008). Repurposing space to better address the needs of the user base helps to ensure that a library is providing adequate service delivery.

\section{Staff Buy-In}

Before any academic library ventures to undertake a weeding project, it is important to get buyin from the staff involved in the project. The literature reveals that a number of human resources related issues commonly arise when weeding projects are implemented at academic libraries (see for example: Dubicki, 2008; Matlak, 2010; Soma \& Sjoberg, 2010). First, there is often a desire among academic librarians to maintain the size of the collection. Since the size of the collection is often equated with prestige, academic libraries are at times resistant to reduce the number of items available (Dubicki, 2008).

A second common issue is related to professional confidence. Librarians often doubt their professional expertise and ability to determine whether or not an item may be needed again in the future (Soma \& Sjoberg, 2010). The process for determining which items should be deselected and discarded is not an exact science (Matlak, 2010). Instances where a book was 
almost discarded, but then requested by a patron may feed the doubt experienced by many librarians. For example, Terrance (2013a) recalls an instance when an item that easily fit into all of the library's weeding criteria was requested by a patron at the eleventh hour (Terrance, 2013a). Yet in one study, less than $7 \%$ of books that were returned to the shelves circulated (Banks, 2002).

Strategies to increase confidence and mitigate doubt can be approached in a number of ways. One of these strategies is to ensure that the institution's collection policies adequately address the deselection process. A well-developed policy creates a framework that can support a librarian's decision to withdraw an item from the collection (Pidgeon, 1995). If librarians know that they are supported by their institutions' policies, it is a first step towards increasing confidence.

Another useful strategy is to consult with and employ the expertise of trusted colleagues (Soma \& Sjoberg, 2010). For example, librarians working in pairs can help to assure one another that decisions made about material are appropriate. It may also be useful to seek outside consultation. In academic libraries, this often includes the participation of relevant faculty members (Dubicki, 2008; Soma \& Sjoberg, 2010). The importance of faculty participation is addressed in more detail in the following section titled, 'Public \& Stakeholder Relations'.

Other barriers to librarian buy-in involve concerns about added work-load. Focus on weeding projects may detract a librarian's attention away from regular duties such as teaching, curriculum design, reference work, and faculty liaison work. Librarians may find that these other tasks take precedence over weeding (Dubicki, 2008). Added workload is also a concern for the often strained members of technical services staff (Soma \& Sjoberg, 2010). This workload can create concern among staff members, or cause them to avoid weeding in the interest of completing other tasks. Several strategies exist for coping with this additional workload. For example, some academic libraries choose to include weeding as part of the ongoing workflow (Soma \& Sjoberg, 2010). This means that weeding becomes a regular part of tasks performed by library staff. Other libraries undertake weeding projects during the summer term, when the demands of teaching, reference and technical services are slightly reduced (Dubicki, 2008). Both options work well, and the chosen method may greatly depend 
on the individual situation of the library in question. However, the integration of weeding into the regular workflow may help to minimize staff concerns about rushing through a weeding project.

Issues related to experience may also arise. If staff members have not participated in a weeding project before, it is important to provide adequate training (Dubicki, 2008). Many libraries choose to prepare documents that explain the rationale for weeding projects, to ensure that staff understand the purpose of and justification for the project (Soma \& Sjoberg, 2010). In addition, checklists are often provided so that staff can compare their decisions to deselect items against a pre-determined set of rules (Dubicki, 2008; Soma \& Sjoberg, 2010). Proper training and guidelines can help staff to make more confident and informed decisions.

Other staff concerns may be related to the demanding physical requirements of a weeding project (Dubicki, 2008). Pulling and moving hundreds, possibly thousands of books can result in painful repetitive stress injuries (Canadian Centre for Occupational Health and Safety, 2003). In addition, many library stacks are harbours of dust, mould and harmful bacteria, which can be disturbed in great quantities during such a project, potentially causing illness (2003). Library management is responsible for properly advising and accommodating staff on how to best mitigate the risk of injury or illness as a result of a weeding project. It is important to consider the physical ability and general wellbeing of staff members participating in a project. Moreover, it is also important to note that able and healthy staff members are not immune to potential injuries or illness. As such, library management should ensure that those who are participating have adequate health and safety protection. To conclude, it is possible to achieve staff buy-in for a weeding project through open consultation, proper training, and thorough planning.

\section{Public \& Stakeholder Relations}

Once the library staff is on board with the project, it is important to consider outside stakeholders. Weeding projects are often a public relations nightmare for libraries. A good example of this is the Christmas Book Tree created at Dalhousie's Killam Library in December 2014 (Mackay, 2014). In this case, members of Dalhousie's community expressed concerns about the practice of weeding after the Killam Library staff used withdrawn print journals to 
build the "Christmas tree" in question. Misunderstandings about the rationale for removing material from the collection can occur easily and escalate quickly (Metz \& Gray, 2005). In an academic setting, the key stakeholders with whom consultations must be considered include (but are not limited to) the faculty, researchers, and students. Misapprehensions between the library and faculty can hurt relations between these two mutually dependent entities and incite unnecessary conflict and politics (Soma \& Sjoberg, 2010). In a worst-case scenario, this can result in a loss of funding for the library and accusations of mismanagement.

With this in mind, it is not recommended to conduct a weeding project in secrecy. Librarians must counteract any potential for misunderstandings by being the first to release information about weeding projects to key stakeholders and/or the public. This allows the library to control the message and address any concerns head-on. Libraries that have taken this approach have been able to successfully manage public understanding about weeding projects. For example, a strong public relations strategy at the Virginia Polytechnic Institute helped the library management to maintain a good rapport with the community while undertaking a weeding project (Metz \& Gray, 2005). One part of this strategy included a form letter kept on hand by library management, used to respond to emails that expressed concern about the project. By adapting this letter to address the specific concerns of each enquiry, librarians were able to clarify the purpose, process and need for the weeding project (Metz \& Gray, 2005). Having this adaptable letter ready was a good way for this library to communicate with concerned members of the public and explain the rationale for the project. Libraries preparing to undertake a weeding project may want to consider similar strategies for managing public perception.

Many concerns about weeding at academic libraries can come from faculty members at respective institutions. One strategy that many academic libraries use to achieve faculty buy-in is to invite faculty members to participate in the process. When the Carl B. Yvisaker Library at Concordia College in Minnesota undertook a major weeding project, librarians used their connections developed through liaison work with the faculty to their advantage (Soma \& Sjoberg, 2010). The librarians distributed a letter explaining the rationale of the project to faculty members, and invited them to participate in the project. After observing first-hand the process used by library staff, faculty members felt more confident that the librarians were 
capable of devising a rational plan for choosing items to withdraw from the collection (2010). In another example, librarians at Columbus State Community College worked in close consultation with faculty members to mitigate misunderstandings. While some departments seemed unconcerned and/or uninterested by the announcement of a weeding project, other faculty members were very concerned that "their" materials would be discarded indiscriminately (Fohl, 2002). The librarians were able to ease concerns about the project by explaining their process for deselecting materials to faculty members. By maintaining open communication and including concerned internal stakeholders in the process, it is possible for collection managers to convey the reasoning for a weeding project.

A collaborative approach to weeding projects may also be an effective way to mitigate community concerns. An example of this occurred at the OLIN library in Florida, where items under consideration for withdrawal were flagged on the shelves of the university library. Users (including librarians, faculty, students and community borrowers) were invited to remove the flag if they wanted the item to stay in the collection (Snyder, 2014). Past projects have demonstrated that collaboration is an effective way to build community confidence in library management (Metz \& Gray, 2005). Since librarians are ultimately trustees of information for our users, inviting users to participate in this important task can be an effective public relations strategy.

Having explored these examples, it is important to note that it may be difficult to achieve a positive response from $100 \%$ of faculty and/or other stakeholders. There will always be at least one person who is vehemently against the process of weeding. However, such instances can be mitigated by a well-timed response from management that demonstrates an appropriate, thoughtful, and evidence-based strategy. If most of the community understands the rationale, then collection managers should not be dissuaded from being open and transparent about conducting weeding projects. The development of any collection of information, library or otherwise, should meet the needs of the user base it seeks to serve. When important decisions about the collection need to be made, it is imperative to develop an effective communications strategy that explains how the process will benefit the users and improve the value of the collection. Public relations play an important role in this aspect of collection management. 


\section{Best Practices for Deselecting Materials}

One way to ensure that there is a sound argument for weeding is to ensure that the methods for deselecting items are in accordance with best practices, and are rooted in evidence-based decision making. Best practices can also help to ensure that a collection is weeded with its users' interests in mind. Much of the recent literature written on weeding, as explored above, is written on a case-by-case basis. While it is helpful for professionals to know about successful weeding projects, there is no recent synthesis of best practices outlined by the professional information management community.

The following best practices are the key elements that appear repeatedly in successful weeding projects detailed by the literature discussed. This section will summarize and reiterate some of the discussion above, and is intended to serve as a take-away guide to weeding printbased materials in an academic library. Each point is numbered in an order recommended by the author. However, different libraries may find that these steps require re-ordering, depending on each individual library's situation.

\section{Ensure that your library's collection policy adequately addresses the deselection process.}

Having a policy that supports the decisions of librarians to remove material from the collection is just as important as the policies that outline collection-building. These policies can also serve as a frame of reference for how to develop project workflows.

\section{Develop a set of criteria to determine which items should be considered for withdrawal.}

As stated previously, common reasons that libraries decide to start a weeding project include, but are not limited to the following reasons:

- Material is now duplicated in a more-accessible electronic format

- Material is outdated or obsolete

- Material has not been used in $\mathrm{x}$ number of years 
- Material is in poor condition and requires replacement

- Material is no longer relevant to the curriculum taught at the institution

Best practices suggest that a multiplicity of criteria is best (Snyder, 2014). This is because factors such as the date of last circulation are not always effective for predicting future use. A better factor to predict future use is "shelf-time," which is the time an item has spent on the shelf between circulations (Slote, 1997). Finally, while it is important to set the criteria for why an item should be weeded, it is also important to outline criteria for why an item should stay in the collection (Dubicki, 2008). These exceptions may include:

- Local interest material

- Material with historical or intrinsic value

- Material that is not held in other libraries

- Material from a special collection that is exempt from weeding

- Items that are considered "classic" or standard to a particular subject area

Exceptions help to preserve unique and rare material, which may add special value to the collection.

\section{Use relevant software to assist with evidence-based decision making.}

Recently, the development of computer-based data collection systems have provided librarians with improved means for understanding how the collection is used. Multiple data points can help librarians to make evidence-based decisions about material in their collection (Snyder, 2014). Many OPAC systems offer usage statistics for library items. Other software and technology can provide additional data analysis of items, including non-circulating material (Welch, Cauble, \& Little, 2000). Not only can this type of data analysis provide a better understanding about the potential future use of material, it can also help to support the rationale for the project, and reduce the labour costs associated with deselection. 


\section{Consult with library staff to achieve internal buy-in.}

Since weeding projects can be a source of concern for many library staff members, it is important to explain, discuss, and develop a weeding plan in consultation with internal stakeholders. Having the support of the library staff can make a potentially challenging project operate more efficiently. The consultation process with staff may include, but is not necessarily limited to, the following strategies:

- Development of internal memos and similar documents that explain the need for and rationale of the project;

- Adequate planning for the mitigation of potential health and safety issues;

- Demonstration by library management that items to be considered for withdrawal have been selected through evidence-based decision making;

- Clear instructions and training on how to identify candidate items for withdrawal.

\section{Develop a workflow suited to your library staff.}

Once internal buy-in has been achieved, it is important to develop a workflow that takes into consideration the current workload of the library's staff. It is important to decide whether a long-term or a short-term weeding project is best suited to the needs of the collection and the current workload of library staff.

\section{Create a Public Relations strategy to address community and stakeholder concerns.}

As discussed above, creating a public relations strategy is much more than just politics for any library. If a library can effectively communicate about its rationale for weeding a collection, the operations of the library become more accountable and transparent to its stakeholders. In addition, good communication can help demonstrate that the library has thoughtful and responsible leadership (Terrance, 2013a). In a best-case scenario, having good public relations has the potential to translate into more stable or increased funding for a library. Useful steps towards creating a good public relations campaign may include: 
- An announcement in the institution's news outlets, such as faculty and student newspapers, explaining in detail the rationale for the project

- Communication to the community about the evidence-based methods used to deselect items

- An invitation to faculty to participate in the weeding process

- Creation of a form letter or email that can be adjusted to meet individual concerns

- Willingness of library management to meet with concerned stakeholders, and give concrete examples of what is being discarded

- Clear communication about what is being done with the discarded materials (e.g., given to charity, recycled, sold at a book sale, given away for free, etc.)

These types of strategies are an effective means for academic libraries to maintain good public relations while undertaking a weeding project.

\section{Flag candidate items to be reviewed, or move them to a holding area.}

Once the weeding project has begun, the project manager should determine whether items to be considered for withdrawal should be flagged on the shelf or moved to a separate holding area. Flagging items on the shelf is a good option if the library has achieved good public relations, and is pursuing a collaborative weeding project with stakeholder involvement. This method is also desirable if a library lacks the space to house temporary items under review. If a library does have space for a holding area, the project manager may choose to have candidate items moved to a temporary location for review.

\section{Have subject specialist and/or faculty members review flagged items and make final decisions.}

Whether a library decides to flag candidate items for withdrawal on the shelf or move them to a temporary holding area, a subject specialist librarian, relevant faculty member or both should review the materials and make the final decision. Having this final review process has the benefit of being an added step where materials are considered before they are withdrawn. This 
is responsible management on the part of librarians. As discussed above, the involvement of faculty members at this stage can be very beneficial, and may lead to faculty recommendations about what areas of the collection could be further developed (Snyder, 2014). This is a good opportunity for subject specialist librarians to draw on the expertise of, and collaborate with, the faculty members with whom they liaise.

\section{Separate items to be discarded and (if necessary) return any items not to be discarded to the shelves.}

Once the subject specialist and/or relevant faculty members have made final decisions for each item, items not bound for discard should be returned to the shelf, while a plan should be developed for those items that will be removed from the collection. The process of discarding deaccessioned materials is another issue, and a synthesis of popular methods are outlined below.

\section{Best Practices for Discarding Materials}

Once a library has selected items to be discarded, the library must decide what is to be done with the unwanted materials. This is an important issue, which if dealt with improperly can cause concerns among internal and external stakeholders. There are other factors to consider, such as environmental concerns and the financial cost of disposal. The following are a list of possible options for librarians to consider when looking for solutions to their discarded print material.

\section{Donate qualified books to charity.}

While not all weeded material is suitable for donation, certain materials may qualify for book donation programs. There are a range of organizations at local, national, and global levels that accept discarded library books, if they meet certain criteria. Examples include Better World Books, Books for Africa, Book Aid, Thrift Books, Zubal Books, correctional facilities and more (Kailova, 2014). Metz and Gray (2005) wrote that the choices made by the Virginia Polytechnic Institute's library to donate much of their weeded material to various charities was an important part of the public relations element of their weeding project (2005). In addition, achieving buyin with internal library staff may also be easier if some of the discarded materials are donated 
to charity. While donating to items to charity is a solution that most people would prefer, not all materials meet the criteria of charitable organizations. Thus, some other options must also be considered.

\section{Develop a book exchange with other libraries.}

At academic libraries, the curriculum may have a large impact on what print-based materials are available. Changes in the faculty members available to teach a particular course, or a shift in the direction of curriculum may affect the usage of certain materials. If this happens, materials that are no longer being used at one library may still be of use at another institution where a relevant course is being taught. In such a case, it may be useful to draw on the library's partnerships with other institutions to develop a book exchange. A successful example of this comes from Columbus State Community College, where the college was able to list discarded items on the OhioLINK listserv (Fohl, 2002). This strategy utilized existing partnerships and was well-regarded by stakeholders.

\section{Sell the books to help raise funds for the library.}

This possibility is slightly controversial. Many libraries are publicly funded, and depending on the jurisdiction of the region, it may be illegal to sell publicly-funded material (Handis, 2007). If, however, this is not the case, some libraries do consider trying to sell material. If it is legal and suitable for the institution, this strategy can help a library to raise funds. There are a number of options for selling ex-library books. The first, and perhaps easiest option to organize is a book sale. Terrance (2013a) recommends that a sale to stakeholders (e.g. students and faculty) should always take place before a sale to external parties, in order to maintain trust in the library (Terrance, 2013a). For an academic library specifically, this would allow students and faculty to purchase material that they find useful, but may not be widely used by the community.

Selling the material online is also a possibility. However monitoring hundreds, possibly thousands, of items online would have significant cost in terms of labour and time. Certain organizations offer to take care of this on behalf of libraries, by collecting and managing the sale of discarded library books. Libraries can receive a percentage of any sales made (for more details on this, see: Kailova, 2014). 


\section{Give the books away for free.}

Many libraries, which cannot find homes for books through the methods noted above, may offer the discarded materials for free to their user base (Soma \& Sjoberg, 2010). However, not all titles will be taken from a free bookshelf. If this is the case, librarians may need to find additional solutions.

\section{Find creative solutions for the books.}

Some libraries have re-used materials by donating them to artists or turning them into artistic projects in-house. An example of this is Dalhousie's Book Tree, created in December 2014 (Mackay, 2014).

\section{Recycle the books.}

Since disposing of large quantities of print materials can have a negative impact on the environment, libraries may find that recycling material that cannot be re-used in any of the above-mentioned solutions is preferable. Librarians may also look to creative recycling projects for solutions. An example of this is the Blockhouse School Project in Nova Scotia, which has been using discarded library materials from Dalhousie University for insulation (The Blockhouse School Project, 2014).

\section{Send books to the garbage.}

There are significant environmental impacts for sending books to a landfill, which may negatively affect stakeholder relations. However, book covers and/or books damaged by mold and mildew are not suitable for any other type of repurposing. As such, garbage disposal may be the only option for some material.

\section{Conclusion}

While unpopular, weeding is an essential part of collection management. Libraries are living entities that change and adapt to the needs of their user base. It is essential that libraries provide relevant and useful information to their users. Weeding is an integral part of reaching this goal. Since weeding is such a controversial topic, it is even more essential that librarians and future librarians understand the delicate nature of the deselection process. This paper has 
sought to address some of the common issues that arise while undertaking a weeding project. These issues include staff buy-in, as well as public and stakeholder relations. In addition, best practices for weeding print materials in an academic library have been identified. This topic could benefit from future research on current weeding practices at academic libraries across Canada. A thorough study could help current information managers in academic settings to share and improve upon best practices for managing this challenge task. As the amount of information generated each day increases exponentially in our digitally networked world, weeding print materials is sure to remain an integral aspect of information resources management. 


\section{References}

Banks, J. (2002). Weeding book collections in the age of the internet. Collection Building, 21(3), 113-119.

The Blockhouse School Project. (2014). The Blockhouse School Project. Retrieved from http://www.theblockhouseschool.org/

British Library. (2014). Legal deposit. British Library. Retrieved from http://www.bl.uk/aboutus/legaldeposit/

Canadian Centre for Occupational Health and Safety. (2003). Health and safety guide for libraries. Hamilton, Ontario: Canadian Centre for Occupational Health and Safety.

Dubicki, E. (2008). Weeding: facing the fears. Collection Building, 27(4), 132-135. doi: http://dx.doi.org/10.1108/01604950810913689

Fohl, C. (2002). Weeding. Community \& Junior College Libraries, 10(3), 47-50. doi: 10.1300/J107v10n03_06

Handis, M. W. (2007). Practical advice for weeding in small academic libraries. Collection Building, 26(3), 84-87. doi: http://dx.doi.org/10.1108/01604950710761643

Kailova, L. (2014). Trash or cash?: Partnering with online booksellers to dispose of deselected academic library monographs. Behavioural \& Social Sciences Librarian, 33(2), 5976. DOI: $10.1080 / 01639269.2014 .904687$

MacKay, M. (2014). Building a book tree or, how and why libraries weed their collections. The Libvine. Retrieved from https://blogs.dal.ca/libraries/2014/12/building-a-book-tree-orhow-why-libraries-weed-their-collections/

Matlak, J. (2010). Weeding older social sciences journals. Behavioral \& Social Sciences Librarian, 29(3), 169-183. doi: http://dx.doi.org/10.1080/01639269.2010.498762

Metz, P. \& Gray, C. (2005). Public relations and library weeding. Journal of Academic Librarianship, 31(3), 273-279.

Pidgeon, A. (1995). On writing a deselection policy: Or, how to toss books without public condemnation. Against the Grain, 86(2), 68-69.

Ronadin, C. Simonsen, L. \& Vogh, B. S. (2009). Low-cost method of removing periodical duplicates using a collection growth formula at a medium-sized academic library. Library Collections Acquisitions \& Technical Services, 33, 119-122. 
Slote, S. J. (1997). Weeding library collections: Library weeding methods. Englewood, Colorado: Libraries Unlimited.

Snyder, C. E. (2014). Data-driven deselection: multiple point data using a decision support tool in an academic library. Collection Management, 39(1), 17-31. DOI: 10.1080/01462679.2013.866607

Soma, A. K. \& Sjoberg, L. M. (2010). More than just low-hanging fruit: a collaborative approach to weeding in academic libraries. Collection Management, 36(1), 17-28. doi: 10.1080/01462679.2011.529241

Steele, K. (2008). Space equals money. The Bottom Line, 21(4), 122-123. doi: http://dx.doi.org/10.1108/08880450810929099

Terrance, L. C. (2013a). Weeding worries, part 1: books. The Bottom Line: Managing library finances, 26(3), 98-102. doi: http://dx.doi.org/10.1108/BL-06-2013-0015

Welch, J.M., Cauble, L. A. \& Little, L. B. (2000). The evolution of technology in the management of noncirculating Library Collections. Technical Services Quarterly, 17(4), 1-11. doi: 10.1300/J124v17n04_01 